\title{
Transversalizando conteúdos de Física no ensino médio: o efeito estufa causado pela pecuária
}

\section{Crossing Physics contents in High School: the greenhouse effect caused by livestock-farming}

\author{
Roberth De-Carvalho ${ }^{1}$. https://orcid.org/0000-0001-6712-1630 \\ Ana Paula Matei $^{2}$. https://orcid.org/0000-0002-6479-2559
}

\begin{abstract}
Resumo: Transversalizar conteúdos em Ciências da Natureza requer um trabalho pedagógico atento de contextualização com a realidade vivencial dos educandos. Nesse sentido, por sequenciamento de ações didáticas no Ensino de Física, compôs-se uma estratégia psicopedagógica com o objetivo de desenvolver uma consciência crítica em um grupo de estudantes de Ensino Médio noturno, abordando uma questão socioambiental: o efeito estufa decorrente de atividades pecuaristas. Em uma abordagem qualitativa e com procedimentos de pesquisa participante, implementou-se um Plano de Ações Pedagógicas Transversais (PAPT) em uma escola pública do município de Blumenau, em Santa Catarina, a partir do qual foram aperfeiçoadas as representações socioambientais nos estudantes. Concluiu-se que o trabalho pedagógico de organização desse sequenciamento didático instigou discursos tecnocientíficos por transições de linguagem dos estudantes quanto ao consumo de animais e seus subprodutos, gerados por atividades agropecuárias, formando concepções críticas para uma cidadania ativa e participativa.
\end{abstract}

Palavras-chave: Transversalidade. Ensino de física. Efeito estufa. Ensino médio. Ação pedagógica.

\begin{abstract}
Crossing contents on Natural Science demands careful pedagogical work for contextualizing with the student's experiential reality. In this regard, in order to organize a didactic sequence in Physics Teaching, a strategy has been deployed to develop the critical awareness of a group of High School student taking classes at night. A socio-environmental question was chosen: the greenhouse effect caused by livestock-farming. With a qualitative approach and participant research, a Cross Pedagogical Action Plan (CPAP) was applied in a public school in Blumenau, Santa Catarina, from which the socio-environmental representations of students were elaborated on. It was concluded that the pedagogical work of organizing the teaching sequence provoked techno-scientific discourses by students' language transitions about the consumption of animal products, generated by livestock-farming, thus forming critical conceptions for an active and participatory citizenship.
\end{abstract}

Keywords: Cross-curricular teaching. Physics teaching. Greenhouse effect. Secondary school. Livestock-farming.

\footnotetext{
${ }^{1}$ Instituto Federal de Educação Ciência e Tecnologia de Santa Catarina (IFSC), Departamento de Infraestrutura, Florianópolis, SC, Brasil. E-mail: roberth@ifsc.edu.br

${ }^{2}$ Secretaria de Estado da Educação de Santa Catarina, Jaraguá do Sul, SC, Brasil.
} 


\section{Introdução}

Inúmeras ações humanas na natureza, marcadamente desde a Revolução Industrial europeia no século 18, vêm compondo diversos cenários de crise ambiental, com destaque para as mudanças climáticas que têm impactado negativamente todos os ecossistemas do planeta. Logo, cumpre ao campo da Educação em Ciências problematizar sobre essas questões socioambientais voltadas à formação de concepções críticas a partir de uma localidade, de um município, de uma região, de um Estado, ou de um país. Tais questões devem figurar transversalmente por conteúdos curriculares das Ciências da Natureza, quer se deem no âmbito de uma aprendizagem científica inicial, ou na produção de sentidos sociais de efeito ecossistêmico.

Desse modo, instruir estudantes para as relações causais dos principais gases que agem na geração do efeito estufa propiciará uma reflexão acerca de determinadas atitudes e comportamentos socioambientais, bem como suas respectivas consequências, atentando-se precipuamente às mudanças climáticas, desde sua realidade local até a dimensão global. Isso possibilitará a formação de estudantes cidadãos, como agentes transformadores de uma sociedade mais sustentável para o futuro, repercutindo posturas, decisões, modos e estilos de vida, além de uma revisão cultural do consumo.

Assim, apresenta-se nesse experimento de pesquisa um acionar didático-pedagógico na disciplina de Física, em uma turma de $2^{a}$ série do Ensino Médio noturno, dentro de uma escola pública no município de Blumenau, em Santa Catarina, buscando promover a transversalidade (BOVO, 2004) a partir de uma questão socioambiental capaz de conscientizar os estudantes para o efeito estufa decorrente de atividades pecuaristas. Esse trabalho didático fora permeado por orientações didático-pedagógicas a partir de documentos norteadores oficiais, como: Parâmetros Curriculares Nacionais do Ensino Médio (PCN) (BRASIL, 1997, 1999, 2002) e da Proposta Curricular de Santa Catarina (SANTA CATARINA, 1998), na área do conhecimento Física, para compreender os encaminhamentos que se destacam em abordagens sobre o tema transversal do meio ambiente no trabalho educacional-pedagógico.

\section{Uma perspectiva do ensino de física}

Em um contexto socioambiental marcado pela degradação do planeta, percebe-se a necessidade de reflexão sobre novas práticas de consumo que reorientem processos, serviços e produtos nos variados setores da economia global. Ademais, em contrassenso com o Protocolo de Kyoto, acordado em fevereiro de 2005 (embora sua criação date de 1997) por 128 dos 192 países signatários da Organização das Nações Unidas (ONU), as emissões de gases do efeito estufa (GEE) cresceram de 16,2\% em sete anos (TUFFANI, 2015). Para tanto, recorrentes compromissos internacionais vêm definindo metas para a redução de emissões que afetam mudanças climáticas, principalmente aos países com economias em transição ao capitalismo, cujos processos produtivos têm contribuído com emissões significativas do dióxido de carbono e do metano.

O Painel Intergovernamental de Mudanças Climáticas (IPCC), órgão das Nações Unidas, responsável por produzir informações científicas, afirma que há $90 \%$ de certeza que o aumento de temperatura na Terra está sendo 
causado pela ação do homem. A partir da Revolução Industrial, o homem passou a emitir quantidades significativas de gases de efeito estufa (GEE), em especial o dióxido de carbono. Neste período, a concentração original de 280 ppm4 deste gás cresceu até os atuais 400 ppm5, intensificando significativamente o efeito estufa. [...] (WWF-BRASIL, 20--?).

Atualmente, uma “[...] importância cada vez maior vem sendo dada à necessidade de se prepararem os estudantes para um futuro sustentável. Assim, espera-se que eles sejam capazes de perceber que as ações de cada um de nós podem refletir na sociedade e no meio ambiente" (CARVALHO et al., 2011, p. 4). Nesse contexto, inserir tais reflexões compete à prática pedagógica escolar, favorecendo o pensamento crítico de estudantes no processo de aprendizagem. Esse caráter de intencionalidade no processo ensino-aprendizagem é sustentado pelos resultados figurados na Organização para a Cooperação e Desenvolvimento Econômico (OECD), através do Programme for International Student Assessment (PISA), situando impressões de estudantes em que

[...] reported that their science teachers frequently use these practices and adapt their teaching to meet students' needs score higher in science, show stronger beliefs about the value of scientific enquiry, and are more likely to expect to pursue a science-related career than students who reported that their teachers use these practices less frequently. (OECD, 2018, p. 10).

Assim, para o Ensino de Física que se propôs nessa experimentação, pretendeu-se promover uma educação pela pesquisa (DEMO, 2011) em que os estudantes possam verificar por suas próprias indagações problêmicas que, para além do $\mathrm{CO}_{2}$ (dióxido de carbono), existem outros gases que interferem no efeito estufa. E que grande parte dessas emissões estão associadas a comportamentos, atitudes, valores e opções de consumo mercadológico. Entretanto, por questões socioeconômicas e políticas, a pecuária ficou ausente do centro da discussão ambiental, mas estudos apontam seu protagonismo no agravamento de efeitos em processos e produtos finais (DOMINGUES; BERMANN, 2012; PRADO; RIBEIRO, 2011; RIVERO et al., 2009).

Nessa orientação temática, buscou-se o alcance de uma concepção ambiental crítica sustentada em De-Carvalho (2000a, 2000b), capaz de desencadear processos psicossociais na busca e orientação de atitudes alternativas, e acionada por procedimentos de pesquisa participante, em Le Boterf (1999), no âmbito da própria localidade dos estudantes. Partindo-se das premissas em De-Carvalho (2000b), relacionou-se o sistema representativo daquela localidade quanto à política e à economia, à ética e à estética, que intervêm diretamente no entorno ambiental. E, criticamente, para aquém de uma concepção utópico-ambientalista que projeta uma sociedade do "não toque" a natureza, porém, despertando para uma cidadania de transformação tecnocientífica e sustentável.

Desse modo, aos conteúdos curriculares em Física se atribuiu o encargo de discutir as causas e os impactos ambientais relacionados à pecuária e ao efeito estufa, projetivos de uma formação cidadã ativa e participante. Diante disso, a metodologia que segue, buscou articular a relação causa-efeito numa perspectiva de ação produtiva da pecuária como núcleo transversal problematizador, a fim de promover a concepção ambiental crítica dos estudantes. 


\section{Metodologia}

Tomou-se como sujeitos desta pesquisa uma amostra de 15 estudantes do Ensino Médio noturno, em sua maioria, economicamente ativos (exercem alguma atividade remunerada), composta por adolescentes e jovens na faixa etária dos 16 aos 18 anos, nomeados aqui como E1, E2... E11, para resguardar sua confidencialidade. Registre-se que o grupo pesquisado tinha um tempo limitado para dedicação aos estudos, por se constituir de trabalhadores cumprindo turnos na indústria e no comércio local, serem pais e mães com filhos pequenos, registrandose, assim, algumas ausências, intercaladamente, em parte nessas ações pedagógicas. Mas, pela divulgação a seus pares, fez com que a maioria do grupo participasse das demais sequências propostas, manifestando grande dedicação, interesse e empenho, implicando o aprendizado de todo o grupo. Por outro lado, embora o universo amostral estivesse no intervalo de 7 a 15 estudantes, este cumpriu satisfatoriamente o sistema causa-efeito para a proposta de desenvolvimento da concepção ambiental crítica naqueles sujeitos.

Desse modo, para suprir o nível de complexidade em uma construção conceitual pelos estudantes, planejou-se, também, uma carga horária extraclasse no decorrer das atividades, para leituras livres sobre situações ambientais quanto ao tema em questão. Logo, organizou-se um ambiente de pesquisa participante (LE BOTERF, 1999), compondo-se um Plano de Ações Pedagógicas Transversais (PAPT). Dessa forma, foram sequenciadas quatro ações, totalizando 11 horas-aula, no $4^{\circ}$ bimestre do ano 2015, conforme descrito no Quadro 1.

Quadro 1 - Plano de ações pedagógicas transversais

\begin{tabular}{|c|c|c|c|}
\hline Ação & Etapa & Descrição & $\begin{array}{l}\text { Data/Tempo } \\
\text { de execução }\end{array}$ \\
\hline 1 & Sondagem inicial & $\begin{array}{l}\text { Problematização e despertamento do grupo } \\
\text { para uma questão socioambiental, visando à } \\
\text { estruturação metodológica das ações. }\end{array}$ & $\begin{array}{l}2 \text { out. } 2015, \\
3 \text { horas-aula }(120 \\
\text { min) }\end{array}$ \\
\hline 2 & $\begin{array}{l}\text { Aproximação } \\
\text { com o problema e } \\
\text { desenvolvimento de um } \\
\text { conceito coletivo }\end{array}$ & $\begin{array}{l}\text { Prognóstico da realidade socioambiental próxima } \\
\text { ao estudante, discutindo o problema levantado a } \\
\text { partir de suas concepções iniciais. }\end{array}$ & $\begin{array}{l}9,16,20 \text { out. } 2015 \\
4 \text { horas-aula }(160 \\
\text { min) }\end{array}$ \\
\hline 3 & $\begin{array}{l}\text { Sistematização/ } \\
\text { apreensão de conceitos } \\
\text { cientificos }\end{array}$ & $\begin{array}{l}\text { Associação de conteúdos científicos, com } \\
\text { aplicação experimental associada à realidade. }\end{array}$ & $\begin{array}{l}23 \text { out. } 2015, \\
1 \text { hora-aula }(40 \mathrm{~min})\end{array}$ \\
\hline 4 & $\begin{array}{l}\text { Socialização/ avaliação } \\
\text { final }\end{array}$ & $\begin{array}{l}\text { Inferências coletivas evocadas ante as } \\
\text { novas concepções críticas sobre a questão } \\
\text { socioambiental em sentido transverso ao } \\
\text { conteúdo de "Radiação Térmica". }\end{array}$ & $\begin{array}{l}27 \text { out. e } 3 \text { nov. } 2015, \\
3 \text { horas-aula }(120 \\
\text { min) }\end{array}$ \\
\hline
\end{tabular}

Fonte: Elaborado pelos autores.

Os registros eram feitos sistematicamente em um diário de bordo, como instrumento para anotação de informações, conversas e observações relevantes no decorrer das ações, ou seja, na sistematização e textualização de impressões. 
Registre-se que as etapas desse sequenciamento didático foram propostas em sua devida autonomia de execução, apresentando níveis de problematização relativamente adequados a cada momento, em particular. No entanto, o alcance de sua complexidade epistemológica se deu na visão da totalidade de cumprimento do processo psicopedagógico, fato esse que alcançou todo o grupo de participantes.

Com intuito de avaliar de forma individual o entendimento dos estudantes a respeito da relação pecuária e efeito estufa, aplicou-se um questionário de questões abertas, referentes à temática.

a) Como você explicaria para alguém sobre as formas desejadas e não desejadas de aquecimento do planeta Terra?

b) As interferências humanas têm implicações em curto e longo prazo em seu babitat. O consumo, a industrialização, o crescimento populacional, tudo é fator de interferência, gerando consequências que, em sua grande maioria, atinge outras gerações. Como você explica as relações do efeito estufa com as atividades da indústria pecuarista?

c) O meio ambiente, a ética e a saúde são temas transversais que podem figurar em diversas discussões sociais, tecnológicas, culturais e científicas. Assim, temos o efeito estufa como tema real abordado em diversas matérias jornalísticas, congressos, simpósios, conferências mundiais e na escola. Como você sugere o estudo desse tema na escola, associando-o às atividades pecuaristas e ao consumo da sociedade?

d) Como você entende a emissão de GEE e de sua responsabilidade quanto às suas práticas de consumo e de trabalho como cidadão(ã)?

\section{Análise e discussão de resultados}

\section{Ação pedagógica 1: sondagem inicial}

Essa ação inicial foi deflagrada pela exposição de um vídeo $A$ carne é fraca (2004), de 54 minutos, com direção e roteiro de Denise Gonçalves, para despertamento/problematização dos estudantes quanto ao processo envolvido na indústria pecuária, incluindo o uso de recursos naturais, como a água e as grandes extensões de terra utilizadas para criação de rebanho bovino. O número de estudantes presente nessa fase foi de 7 (46,7\%).

Nesse sentido, pode-se perceber que a ação promoveu um despertamento crítico nesse grupo quanto ao poder de influência que a indústria midiática tem junto à população. "Os reflexos sobre as concepções dos alunos são diretos, como leitores, ou indiretos, através dos canais sociais pelos quais ocorre a difusão das informações jornalísticas" (XAVIER; KERR, 2004, p. 345).

Assim, organizando-se uma mesa redonda, pode-se constatar a falta de conhecimento deles quanto aos métodos e recursos naturais empregados, gerando surpresa quanto à quantidade de grãos e água consumidos pela indústria pecuária, “[...] enquanto existe tanta gente passando fome [...]" (E1), registrado na fala desse estudante. 


\section{Ação pedagógica 2: aproximação com o problema e desenvolvimento de um conceito coletivo}

Nessa etapa da pesquisa, foram abordados os processos físicos relacionados com o efeito estufa. Para isso, utilizaram-se slides estruturados com imagens para melhor esclarecimento dos conceitos. Muitos relataram que não tinham noção sobre o uso do solo, consumo de alimentos e água utilizada nesse processo, compreendendo de forma transversal no contexto curricular de Física que isso impacta diretamente nesse fenômeno. Com os dados do Instituto Brasileiro de Geografia e Estatística (IBGE) e da ONU apresentados nesses slides, a turma pôde quantificar o consumo global presente na pecuária. Assim sendo, enfatizou-se aos estudantes que o objetivo principal das ações seria promover o senso crítico e reflexivo deles no que diz respeito à interferência do ser humano e seus modos de produção relacionados à pecuária. Portanto, formando cidadãos conscientes de suas ações no meio que interferem com suas atitudes e comportamentos.

Essa fase despertou grande empolgação inicial por parte de alguns estudantes, sugerindo que esses "dados alarmantes", conforme levantado, fossem divulgados para além do espaço escolar. Eis a formação de uma concep̧̧ão ambiental crítica (DE-CARVALHO, 2000a) que se perfaz no anseio implícito do cidadão em uma educação para todos. Propôs-se a realização de um seminário com a comunidade local, apresentando as estatísticas que envolvem o impacto ambiental da pecuária. Em seguida, aplicou-se um questionário (12; 80\%) a cada participante, contendo questões relacionadas às atividades pecuaristas e às responsabilidades cidadãs quanto às práticas de consumo e de trabalho.

Segundo relato de um estudante ao responder sobre as relações entre efeito estufa e pecuária, ele argumentou que:

E2: Para conseguir atender altas demandas, devido [sic] ao crescimento populacional, alimentam-se as indústrias pecuaristas. Por exemplo: com mais pessoas consumindo é necessário mais alimento, e hoje em dia um dos principais alimentos consumidos no Brasil, e em muitos lugares, é a carne. Assim, é necessário desmatar muito, e com tantos desmatamentos realizados para a plantação de soja (alimento dos animais), epara pastos etc., a pecuária contribui muito para o efeito estufa. [sic].

Outro estudante concluiu que o fenômeno "é um ciclo da pecuária, o desmatamento para pastagem dos bois, para a plantação da soja que alimenta eles [sic], a água que é usada nesse processo todo?' (E3). E, portanto, em decorrência desse processo, também foi colocado: “aquecimento global, fazendo as geleiras derreterem [sic], aumentando o nivel do mar." (E4).

O caráter formativo escolar emerge como tônica e transita como processo diretor de ideias, concepções, construções conceituais, políticas, ideofilosóficas, compondo o repertório de competências culturais, científicas e tecnológicas necessárias ao perfil do educando (DECARVALHO, 2000a, 2000b) formando uma cidadania ativa e participativa, ante as concepções críticas dos seus sujeitos. 


\section{Ação pedagógica 3: sistematização/apreensão de conceitos científicos}

Um modo didático de ilustrar o processo físico de retenção de calor do efeito estufa foi tomado experimentalmente, no qual a turma pôde sistematizar e materializar os conceitos físicos envolvidos no processo de radiação térmica, previamente abordado em uma aula expositivo-dialogada (15 min).

Nessa ação, preparou-se o grupo apresentando a função dos materiais que seriam utilizados, sendo: luminária com lâmpada de $60 \mathrm{~W}$, dois copos com água, papel alumínio, caixa de sapato, em papelão, tesoura e filme de material plástico. Esse conjunto de materiais de fácil aquisição foi utilizado na montagem do Simulador do efeito estufa (FARIAS, 2015).

Durante o experimento, foram analisando a função e a relação dos objetos utilizados com o comportamento do planeta quanto ao efeito estufa. O papel da luminária no contexto foi rapidamente compreendido e relatado pela turma como a fonte de energia/ calor representativa do Sol. Quando perguntado para o grupo a utilidade do papel alumínio, enquanto alguns falaram refletir o calor, o E5 colocou que o "papel aluminio representaria, por exemplo, as geleiras que exerce [sic] o mesmo efeito no Planeta", denotando a reflexão por analogia dessa prática experimental (DEMO, 2011). Assim sendo, verificou-se que o mais relevante ao utilizá-la como ferramenta didática é que por meio de objetos simples e de uso cotidiano houve uma associação com o efeito estufa, alcançando o objetivo pretendido com essa ação, pela associação do fenômeno em esfera global.

$\mathrm{Na}$ ação, com a luminária ao representar a fonte de energia/radiação e o papel filme, indicando a presença da atmosfera protetora, esclareceu-se que ela deve formar uma camada especifica, porém, com a intensa emissão de GEE, este quadro está se alterando fisicamente. Para E6: "Os gases são cada vez mais emitidos e a 'capa' fica mais espessa", retendo mais calor no Planeta.

Importante registrar que, quando um estudante aprende a lidar com o método experimental, planejando-o e o executando, bem como a argumentar e a contra-argumentar os resultados de um experimento, fundamentando a autoridade contida nesses argumentos, não se está apenas "fazendo ciência", mas também se apropriando e investindo, epistemologicamente, tal fazer a partir do e no mundo, textualizando e inferindo novas representações para o acionar da cidadania de forma mais crítica em um dado contexto problematizador (DE-CARVALHO, 2000a; DEMO, 2011).

\section{Ação pedagógica 4: socialização/avaliação final}

A fase final do processo de pesquisa se deu por uma socialização de conhecimentos adquiridos e gerados no decorrer das ações pedagógicas transversais. Para tanto, a turma foi dividida em dois subgrupos, sendo orientada a confeccionar materiais ilustrativos que comunicassem suas apreensões e inferências para o coletivo escolar, ou seja, suas concep̧̧̃óes ambientais críticas. Vale ressaltar que, de maneira geral, o grupo participante da pesquisa assimilou o fenômeno do efeito estufa como um processo natural de aquecimento da Terra, porém, exacerbado de sua natureza ecológica, por fatores antrópicos (WWF-BRASIL, 201--?). Ao explicar sobre as formas desejadas e não desejadas de aquecimento do planeta Terra, segundo argumentos de dois estudantes, tem-se que: 
E7: As formas desejadas é que sem esse aquecimento natural não haveria vida, só que existe o lado ruim, com a radiação solar, os gases presentes na atmosfera eles vibram muito (sic) e esquenta o planeta, o problema que esses gases estão em muita quantidade, assim quando a radiação chega nesses gases, liberando mais calor.

E8: O planeta Terra precisa ter certa temperatura, um determinado calor. [...] Mas as indústrias a produção enorme de gases e utensílios que são maléficos a natureza [sic] $e$ o mau controle da fiscalização têm causado o derretimento das geleiras e o aquecimento do planeta.

As informações e os assuntos abordados pelos estudantes no decorrer dessa etapa contemplaram as relações existentes entre a indústria pecuária e o efeito estufa, desde o desmatamento para plantação de grãos e pastagens, transitando ao comportamento dos gases envolvidos no processo (saberes científicos e conceituais). Essas relações entre a criação de animais para abate e seus subprodutos interferem diretamente no desmatamento em função da plantação de grãos para abastecer a indústria pecuária. Domingues e Bermann (2012) registram que foram destruídos 70 mil km², de 2002 até abril de 2006 da Floresta Amazônica, pertencente ao Estado do Mato Grosso. O impacto dessa destruição envolve a extinção de muitos animais e plantas (diversos ecossistemas) e a liberação de muitos gases poluentes. Houghton (2005 apud MICOL; ANDRADE, BÖRNER, 2008) situa que o desmatamento representa cerca de $26 \%$ do total de emissões de $\mathrm{CO}_{2}, 48 \%$ de $\mathrm{CH}_{4}$ (metano) e $33 \%$ de $\mathrm{N}_{2} \mathrm{O}$ (óxido nitroso), e, assim, contribui, finalmente, com $27 \%$ do aumento de efeito estufa provocado por ações antrópicas.

Portanto, conforme apresentado em dados científicos, a turma participante na pesquisa, de modo geral, retratou a relação da pecuária com os GEE. Segundo observações de estudantes, ao explicarem que

E9: Os animais liberam metano e lembrando que no processo da pecuária é consumido muitos produtos que liberam gases. [sic]

E10: Tudo começa na alimentação desses animais porque acabam com a floresta para plantar soja para eles, e para o tanto de água que gasta para plantar a soja. [sic].

A quantidade de água utilizada na produção pecuarista impactou grande parte do grupo. Segundo documento do Programa das Nações Unidas para o Meio Ambiente (2008), para a produção de $1 \mathrm{~kg}$ de arroz, por exemplo, requer-se 3.500 litros de água, e, $1 \mathrm{~kg}$ de carne consome cerca de 15.000 litros de água. A pecuária seria responsável, então, por $18 \%$ do consumo de água. Tais relações de produção-consumo devem ser discutidas com os estudantes, problematizando os impactos ambientais de toda ordem.

Assim, as mudanças climáticas e os seus efeitos interessam basicamente a todos: o que está em discussão não é o conforto ou estilo de vida, mas a sobrevivência. [...] Os cientistas nunca tentaram esconder a realidade exposta em suas pesquisas. O perigo que ameaça a Terra nunca foi mantido em segredo. Eles tentaram insistentemente apresentá-lo de todas as maneiras 
possíveis, inclusive por intermédio de meio de comunicação de massa. (PROGRAMA DAS NAÇÕES UNIDAS PARA O MEIO AMBIENTE, 2008, p. 23).

O entendimento dos estudantes participantes do PAPT chega à conclusão de que cada pessoa tem sua parcela de interferência nesse cenário. Logo, conforme colocou um estudante:

E11: [...] deveríamos ter um sistema aonde (sic) emissões de GEE fossem reguladas, tanto nas fábricas e no consumo do cotidiano. Pois de fato somos bilhões e se cada um, quanto en buscamos a responsabilidade, teremos um planeta melhor. [...] Mas se continuar infelizmente as novas gerações sofrerão as consequências.

Analise-se que, considerando que tal abordagem transversal fora desenvolvida em nível microcurricular, há uma tendência representativo-conceitual nas transições de linguagem dos estudantes quanto à proposição de uma ação educacional mais interventiva, intencional e sistêmica quanto ao desenvolvimento de um pensamento coletivo e solidário com o ambiente que deve ser socialmente partilhado. De tal forma, o processo de transversalidade didática, promotora de transições de linguagem, efetivou-se satisfatoriamente dentro da execução do PAPT, conforme avaliado. Veja-se que, além do alcance de saberes científicos convertidos em saber apreendido, compreendeu-se o desenvolvimento de uma postura crítico-social e cidadã muito ativa e mais inquieta.

\section{Considerações finais}

Cumprindo-se o alcance de uma concepção crítica voltada à formação cidadã ativa e participativa, as ações pedagógicas aqui propostas aproximaram, pela via da transversalidade temática, o grupo de estudantes participantes da pesquisa a uma realidade cotidiana, gerada por comportamentos e atitudes de produção e consumo mercadológicos: o processo de emissão de GEE pela pecuária. As discussões, os estudos e a experimentação promoveram uma articulação psico-cognitiva com a problemática apresentada, capaz de estruturar conceitos científicos (leis que regem os comportamentos dos gases) às suas aplicações em situações cotidianas que implicam o modo de vida, o consumo das pessoas, as referências de economia e de trabalho, o uso e ocupação do solo, enfim, fazendo-os inferir sobre novos elementos interferentes em um processo que, primeiramente, foi iniciado em sua simplicidade científica.

Com relação ao estudo dessa questão socioambiental na escola, o grupo amostral levantou questões suficientemente comprobatórias dessas ausências problematizadoras dentro de conteúdos de Física, e em outras Ciências, sugerindo (via questionário aplicado) e ampliando suas abordagens, por transições de linguagem geradoras de discursos socioambientais, inferindo que se deve:

- Conscientizar as pessoas com palestras e mostrando a realidade;

- Promover eventos como "O dia sem carne", para maior economia de água;

- Educar para um consumo consciente; 
- Expor publicamente documentários (como, por exemplo: "A carne é fraca") que além de mostrar sobre o efeito estufa, abordem outras problemáticas;

- Conscientizar outros estudantes sobre como acontece o efeito estufa, para que coletivamente possam tomar algumas atitudes que, por mais situadas que sejam, serão bastante significativas no todo;

- Desenvolver pesquisas de comportamento (com audições, questionários, entrevistas) sobre o quanto cada um consome de alimentos, produtos, carros e outros bens e, em decorrência dos resultados, propor um sistema para minimizar os gastos dos mesmos;

- Associar sempre temas dessa natureza à nossa realidade, porque não há como se desviar, tem-se que combater e solucionar;

- Promover palestras para os alunos para esclarecimento do assunto, gerando a postura de maior contenção e/ ou recusa no consumo de carne animal;

- Abordar o assunto em outros espaços escolares;

- Incluir a temática desde o começo do ensino fundamental, para que todos possam compreender suas ações sobre o efeito estufa; $e$,

- Incentivar e praticar atividades como: plantar árvores, visitar fazendas e cuidar do jardim, promovendo um melhor aprendizado para o tema. [sic]

Avalia-se, nesse processo de transição de ideias, sugestões, soluções socioambientais, alternativas de implementação curricular, além de iniciativas de pesquisas de atitudes e hábitos de consumo das pessoas, levantadas pelos estudantes, que, pela via da construção discursiva, revelou-se o alcance de uma consciência crítica almejada no PAPT. Bem como um processo dialógico para a intervenção cidadã, reiterando-se como ativo e participativo, e cooptado por esses sujeitos em uma visão de educação para toda a sociedade, para além dos espaços formais. Tudo isso é marcado por conceitos e indicadores nesses discursos socioambientais e tecnocientíficos, cumprindo o sistema causa-efeito que se propôs no âmbito do sequenciamento didático.

Além disso, vê-se nas sugestões desses estudantes uma carência de ações pedagógicas que promovam metodologias mais críticas, dinâmicas, socioconstrutivas, dialógicas e contextualizadoras da realidade factual de vivências. Os caminhos de orientação transversal nessas abordagens problematizadoras foram a gênese do efeito representativo-conceitual requerido no PAPT, dado pelo sequenciamento intencional das ações propostas. E, no caso dessa pesquisa participante, a geração de discursos sobre o efeito estufa produzido por atividades pecuaristas.

De outra forma, cumpre salientar, como foi ressaltado na metodologia desta pesquisa, que o número de participantes, mesmo tendo variado de 7 (46,7\%) a 15 (100,0\%), em alguns momentos, interlacadamente durante as ações pedagógicas, não interferiu no processo de sequenciamento e qualidade de desenvolvimento discursivo e pedagógico. Isso foi possível uma vez que esse sequenciamento foi proposto por etapas compreendidas em sua devida autonomia de execução, apresentando níveis de problematização relativamente adequados a cada uma, em particular, embora, no entanto, o alcance de sua maior complexidade epistemológica tenha se dado na visão integrada desse processo psicopedagógico. E isso foi seguramente registrado nas respostas aos questionários, por $80 \%$ de seus participantes, bem como nos momentos de participação intercalada, por aqueles ausentes (3), que marcaram discursos tecnocientíficos e socioambientais proporcionalmente críticos, relativamente aos demais.

Ausências e atrasos eram superados por leituras complementares (extraclasse), bem como por retomadas recorrentes ao objeto em estudo, em cada etapa, demandando a plena participação dos presentes. 
Por fim, essa pesquisa contribui para um olhar mais crítico em relação ao consumo consciente de recursos ambientais (produzidos ou reproduzidos), contemplando o potencial de aspectos curriculares em transversalidade, dentro do ambiente de formação escolar. E, portanto, para um Ensino de Ciências mais crítico e contextualizado. Pela articulação de temas transversais não restritos a parâmetros ou a diretrizes predeterminadas, mas, principalmente, conferindo novas possibilidades de abordagens problematizadoras de cunho socioambiental, para a formação de representações crítico-reflexivas nos estudantes. Eis a tarefa principal de todo educador: transcender o senso comum de execução curricular e promover o caráter de construção coletiva de conceitos tecnocientíficos, com viés socioambiental crítico nos discursos advindos de aprendizagens dos estudantes.

\section{Referências}

BOVO, M. C. Interdisciplinaridade e transversalidade como dimensões da ação pedagógica. Urutágua, Maringá, n. 7, p. 1-11, 2004. Disponível em: http://www.urutagua.uem. br/007/07bovo.htm. Acesso em: 27 fev. 2019.

BRASIL. Ministério da Educação. Parâmetros curriculares nacionais: ambiente, saúde. Brasília: MEC: SEF, 1997. v. 9.

BRASIL. Ministério da Educação. Parâmetros curriculares nacionais ensino médio: ciências da natureza, matemática e suas tecnologias. Brasília: MEC: SEF, 1999. v. 3.

BRASIL. Ministério da Educação. PCN+ensino médio: orientações educacionais complementares aos parâmetros curriculares nacionais: ciências da natureza, matemática e suas tecnologias. Brasília: MEC: SEB, 2002.

A CARNE é fraca. Direção e roteiro: Denise Gonçalves. Produção: Instituto Nina Rosa. São Paulo: Instituto Nina Rosa, 2004. Mini DV (54 min), color.

CARVAlHO, A. M. P. et al. Ensino de física. São Paulo: Cengage Learning, 2011.

DE-CARVALHO, R. Estratégia metodológica de educação ambiental na disciplina saneamento do curso superior de licenciatura plena em construção civil do CEFETMA. Dissertação (Mestrado em Pedagogia Profissional) - Centro Federal de Educação Tecnológica do Maranhão, São Luís, 2000a.

DE-CARVALHO, R. A gestão microcurricular na educação ambiental. In: CAMPELLO, J. E.; DOUSSU, L. (org.). Pedagogia profissional. São Luís: Imprensa Universitária, 2000b. p. 21-39.

DEMO, P. Educar pela pesquisa. 8. ed. São Paulo: Autores Associados, 2011.

DOMINGUES, M. S.; BERMANN, C. O arco de desflorestamento na Amazônia: da pecuária à soja. Ambiente \& Sociedade, São Paulo, v. 15, n. 2, p. 1-22, 2012. Disponível em: https://dx.doi.org/10.1590/S1414-753X2012000200002. Acesso em: 27 fev. 2019.

FARIAS, I. D. Atividades de ciências da natureza: simulador do efeito estufa. São Paulo: USP: UNIFESP, [2015]. Disponível em: http://www.cienciamao.usp.br/tudo/exibir. php?midia=lcn\&cod=_geocienciassimuladordoef. Acesso em: 22 dez. 2017. 
LE BOTERF, G. Pesquisa participante: propostas e reflexões metodológicas. In: BRANDÃO, C. R. (org.). Repensando a pesquisa participante. São Paulo: Brasiliense, 1999. p. 51-68.

MICOL, L.; ANDRADE, J.; BÖRNER, J. Redução das emissões do desmatamento e da degradação (REDD): potencial de aplicação em Mato Grosso. Alta Floresta, MT: ICV, 2008.

OECD. PISA 2015: results in focus. [S. l.]: OECD, c2018. Disponível em: http://www.oecd. org/pisa/pisa-2015-results-in-focus.pdf. Acesso em: 20 dez. 2018.

PRADO, G. B.; RIBEIRO, H. Pecuarização na Amazônia e consumo de carne: o que está por trás? Saúde e Socidade, São Paulo, v. 20, n. 3, p. 730-742, 2011. DOI: https://doi. org/10.1590/S0104-12902011000300017.

PROGRAMA DAS NAÇÕES UNIDAS PARA O MEIO AMBIENTE. Mude o hábito: um guia da ONU para a neutralidade climática. [S. l.]: PNUMA, c2008.

RIVERO, S.; ALMEIDA, O.; ÁVILA, S.; OLIVEIRA; W. Pecuária e desmatamento: uma análise das principais causas diretas do desmatamento na Amazônia. Nova Economia, Belo Horizonte, v. 19, n. 1, p. 41-66, abr. 2009. DOI: https://doi.org/10.1590/S010363512009000100003.

SANTA CATARINA. Secretaria de Estado da Educação e do Desporto. Proposta curricular de Santa Catarina: educação infantil, ensino fundamental e ensino médio. Florianópolis: COGEN, 1998.

TUFFANI, M. Dez anos depois, Protocolo de Kyoto falhou em reduzir emissões mundiais. Folha de S. Paulo, São Paulo, 16 fev. 2015. Ambiente. Disponível em: http://www1.folha. uol.com.br/ambiente/2015/02/1590476-dez-anos-depois-protocolo-de-kyoto-falhou-emreduzir-emissoes-mundiais.shtml. Acesso em: 24 jan. 2018.

WWF-BRASIL. As mudanças climáticas. [S. l., 20--?]. Disponível em: https://www.wwf. org.br/natureza_brasileira/reducao_de_impactos2/clima/mudancas_climaticas2. Acesso em: 5 ago. 2018.

XAVIER, M. E. R.; KERR, A. S. A análise do efeito estufa em textos para-didáticos e periódicos jornalísticos. Caderno Brasileiro de Ensino de Física, Florianópolis, v. 21, n. 3, p. 325-349, 2004. Disponível em: https://periodicos.ufsc.br/index.php/fisica/article/ view/6423. Acesso em: 5 ago. 2018.

Artigo recebido em 25/03/2018. Aceito em 25/08/2018.

Contato: Avenida Mauro Ramos, 950, Centro, Florianópolis, SC, 88020-300, Brasil. 